\title{
Analysis of Node Density and Pause Time Effects in MANET Routing Protocols using NS-3
}

\author{
Lakshman Naik.L \\ Indian Institute of Technology (Banaras Hindu University)/Department of Electronics Engg., Varanasi, 221005, India \\ E-mail: lnaikl@bhu.ac.in \\ R.U.Khan ${ }^{1}$ and R.B.Mishra ${ }^{2}$ \\ Indian Institute of Technology (Banaras Hindu University)/Dept. of Electronics Engg. ${ }^{1}$, Dept. of Computer Science and \\ Engg. ${ }^{2}$, Varanasi 221005, India \\ E-mail: $\{$ rukhan.ece, mishravi.cse $\} @$ iitbhu.ac.in
}

\begin{abstract}
Networks which function without having any centralized fixed infrastructure or central administration are called MANETs (Mobile Ad hoc Networks). These networks are formed by small or large set of mobile nodes and communicate through the wireless links. Such Networks requires best routing protocols to establish error-free and efficient communication links. MANETs has the property of dynamically changing topology due to their mobile nodes, which move from one place to another. Overall performance of MANET routing protocols depends upon various network and protocol parameters. Mobile ad hoc networks have the characteristics of self-forming and self-healing. The routing algorithms of the routing protocols ensure selection of routes and connectivity between the mobile nodes. This paper presents analysis of three well known routing protocols of MANETs, namely; AODV (Ad hoc On Demand Distance Vector), DSDV (Destination Sequenced Distance Vector) and OLSR (Optimized Link State Routing). Analyses of these routing protocols have been carried out using NS-3 (Network Simulator-3) by varying node density and node pause time. Different performance metrics such as throughput, packet delivery ratio, end to end delay, packet loss and normalized routing load have been considered for this analysis. This analysis concludes better performance of the OLSR routing protocol.
\end{abstract}

Index Terms - Throughput, Packet delivery ratio, End to end delay, Packet loss Routing, Simulation, NS-3 (Network Simulator -3 ).

\section{INTRODUCTION}

A mobile ad-hoc network often referred as MANET is a set of wireless nodes which move freely from one point to another without having any fixed infrastructure $[1,2]$. These are self-forming and self-healing networks, nodes of such networks are mobile in nature, hence they acquire dynamic network topologies. In MANETs, any node can openly establish connection with the other nodes of the network with in the transmission range of the other nodes. Mobile ad hoc networks are lively subject of popular researches because of their application in Wi-Fi/802.11 supported portable devices that become extensive [3]. The aim behind all such new research is to improve performances of MANETs by improving performances of their routing protocols with the help of routing algorithms. MANET survivability varies with different routing protocols. Their survivability is also depends on factors like; node density, node pause time, varied transmission power and node mobility speed etc. MANET routing protocols are designed to regulate efficient and error free route links between the mobile nodes. Advancement in technology have achieved performance improvements in small, mobile-wireless devices like laptops, mobile phones etc. [4]. Based on procedure of route discovery, these routing protocols are classified into three types; proactive or table-driven, reactive or on-demand and hybrid. Hybrid routing protocols are developed by combining the features of proactive and reactive routing protocols [5].

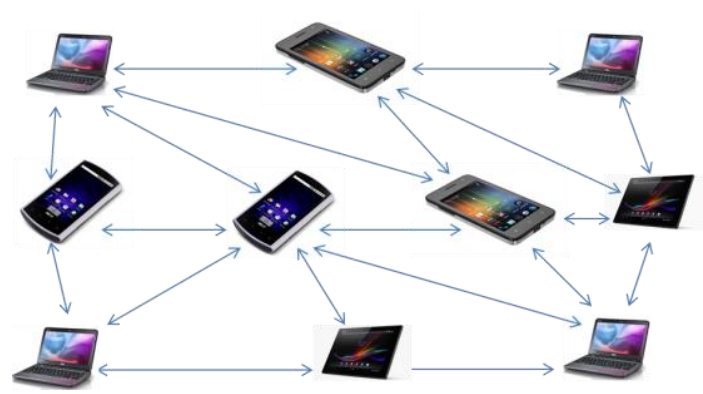

Fig.1. Mobile Ad-hoc Network

In mobile ad-hoc networks, mobile nodes communicate each other using multi hop wireless links. These networks are usually deployed for various diverse applications like; military networks, conference rooms and in commercial applications like vehicle ad-hoc networks [6]. Due to mobility nature of the nodes, the physical network topology of these networks often changes randomly. MANETs do not possesses any stationary infrastructure like access points or base stations, thus, every node acts as router. These routers forward the progressing data packets to all their neighboring nodes. The well-known MANET routing protocols are; AODV (Ad hoc On 
Demand Distance Vector), DSDV (Destination Sequenced Distance Vector), OLSR (Optimized Link State Routing), DSR (Dynamic Source Routing), and TORA (Temporally Ordered Routing Algorithm) [7, 8, 9, $10,11,12,13]$. Performance of these routing protocols depends upon various factors like; complex interplay of the protocol mechanisms and their specific parameter settings with traffic intensity, mobility, node density and conduct of the mobile wireless nodes. This paper presents simulation based analysis of AODV, DSDV and OLSR routing protocols with varied number of nodes and their pause time in different scenarios. Over the last few years, various MANET routing protocols have been developed and presented by the researchers. These researches improved their performance with respect to establishing error free and efficient routes between the nodes. We have carried out this analysis to study node density and node pause time effects in AODV, DSDV and OLSR. Our upcoming research will focus; presenting improved version of these routing protocols. This paper presents related works in section II, MANET routing protocols in section III, performance calculating matrices in section $\mathrm{IV}$, simulation tools in section $\mathrm{V}$, results and discussions in section VI and conclusions in section VII.

\section{RELATED WORKS}

Many researchers have studied comparative analysis of MANET routing protocols and presented their results to the research community for further research. Most of them used NS-2 (Network Simulator-2) in their analysis. Some of such research works have been discussed here. Teressa Longjam and Neha Bagoria have studied comparative analysis of DSDV and AODV and declared better performance of DSDV as per their simulation scenarios [14]. Rakesh Kumar Jha and Pooja Kharga have studied comparative analysis of OLSR, AODV and DSR, their conclusion states better performance of AODV [15]. D.Kumar \& S.C.Gupta have studied transmission range, density \& speed based performance analysis of OLSR, DSR and ZRP (Zone Routing Protocol). Based on their analysis and network scenarios, they concluded better performance of DSR [16]. Rajneesh Kumar, Jitender Grover and Anjali have studied analysis of network survivability with variable transmission range and mobility on AODV over MANET, their conclusion declares that the AODV has better performance with highest node mobility speed and higher transmission ranges; in terms of network survival and QoS parameters [17]. Researchers Ali Khosrozadeh, Abolfazle Akbari, Maryam Bagheri and Neda Beikmahdavi have studied conventional AODV routing protocol, their analysis have presented a new algorithm of AODV to the research community [25]. Some researchers have worked on solution to the energy constraints in mobile ad-hoc network protocols. Researchers D.Loganathan, P.Ramamoorthy have studied DSDV routing protocol, they presented the multicast parameters based DSDV (MPB-DSDV) routing protocol to enhance the energy efficient of ad hoc networks [26]. Researchers Charles E.
Perkins, T.J. Watson and Pravin Bhagwat have proposed an ad-hoc network which has supportive appointment of set of mobile nodes without the requisite involvement of any centralized base station or access point. Charles E. Perkins presented a state-of-the-art design for the ad-hoc networks operation. The indication behind the design is to make each mobile node as a specialized router. These nodes periodically announce their interconnection topology information with their neighbouring nodes and other mobile nodes within the network. These extents to a new kind of routing protocol in mobile ad-hoc networks. Charles E. Perkins has examined amendments to the basic Bellman-Ford routing mechanism, as quantified by conventional RIP (Routing Information Protocol), to mark it appropriate for a dynamic and self-starting network appliance for user's choice. These modifications address looping issues of conventional Bellman-Ford techniques, and helpful for the broken links [27].

\section{MANET ROUTING PROTOCOLS}

Here, in this paper, we present simulation based study and analysis of AODV, DSDV and OLSR routing protocols. These routing protocols are liable to establish the correct and efficient routes among the mobile nodes in MANETs. Routing is a process which discovers the error free and efficient routes between a source node and the destination node; it makes sure correct and timely delivery of data packets.

\section{A. Ad-hoc on demand distance vector (AODV)}

AODV is developed for mobile ad-hoc networks and other wireless ad-hoc networks. It is a reactive routing protocol; AODV was developed by C.Perkins, S.Das and E.Belding-Royer during July 2003 [18]. In ad-hoc on demand distance vector routing, discovery of route takes place subjected to route requests received from the neighboring nodes and other nodes in the network [19]. AODV maintains newest routing information by means of route discovery procedures and updated routing tables [20]. In AODV, path discovery takes place when a source node transmits RREQ (Route Request) message throughout the network until required destination reached.

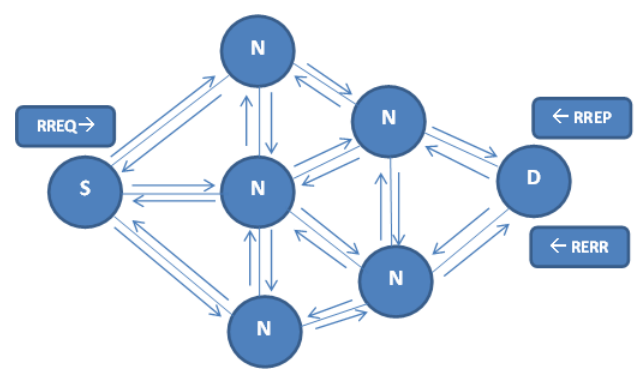

Fig.2. Message Transmission in AODV

Upon receiving RREQ message, the destination node generates RREP (Route Reply) message for the source node to ensure the path. During path breaks, the destination node generates a RERR (Route Error) message and transmits it throughout the network so that 
every node receives it. In Fig. 2, the source node ' $\mathrm{S}$ ' is transmitting RREQ message, whereas the destination node ' $\mathrm{D}$ ' is transmitting RREP message throughout the network of mobile nodes ' $N$ '. The destination node ' $D$ ' generates RERR message when path break occurs between the source node ' $S$ ' and the destination node ' $D$.

\section{B. Destination sequenced distance vector (DSDV)}

DSDV is one of the proactive routing protocols of the MANETs. DSDV is an altered version of DBF (Distributed Bellman Ford) technique. This technique is used to calculate the shortest path. The conventional DBF technique creates certain routing loops during the routing process. The DSDV was developed to suppress this looping problem with the help of DSN (Destination Sequence Number) [21]. DSDV is similar to the RIP (Routing Information Protocol), excepting the DBF technique. In DSDV, mobile nodes transmit updated routing information and incremented sequence number throughout the network. Route selection process is carried out by the distance vector shortest path algorithm. DSDV minimizes its transmission overheads by using two updated packets namely; "full dump" and "incremental dump". The full dump packet holds the routing data, whereas the incremental dump holds only the changed data successively since the previous full dump.

\section{Optimized Link State Routing (OLSR)}

OLSR is one of the proactive protocols of the mobile ad hoc networks. OLSR was developed based on link state routing algorithm; OLSR uses optimized technique to extract information pertaining to the network topology [22]. In optimized link state routing, when there is a change in network topology occurs, flooding of information to all the network nodes happens. These flooding are minimized by the help of MPR (Multi Point Relays). Table-driven nature of the OLSR helps to broadcast updated routing tables to all the mobile nodes of the network. Various control messages are used in OLSR routing protocol; HELLO, TC (Topology Control), HNA (Host and Network Association) and MID (Multiple Interface Declaration). The OLSR broadcasts these control messages periodically that is why OLSR does not require usage of control message delivery. This aids OLSR to have reasonable losses in control messages.

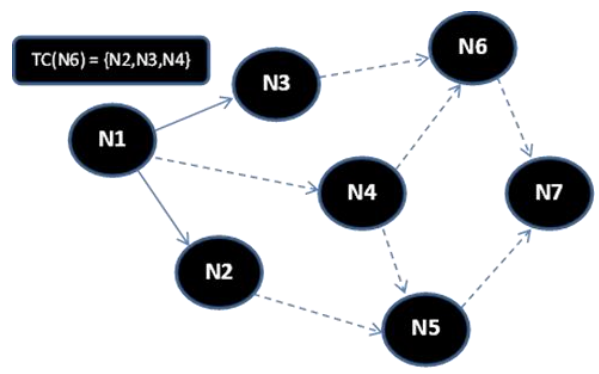

Fig.3. Control Message Transmission in OLSR

Fig. 3 illustrates the processing of TC message from the node $\mathrm{N} 1$ to the network of seven mobile nodes $\mathrm{N} 1, \mathrm{~N} 2$,
$\mathrm{N} 3, \mathrm{~N} 4, \mathrm{~N} 5, \mathrm{~N} 6$ and $\mathrm{N} 7$, where $\mathrm{N} 2, \mathrm{~N} 3$, and $\mathrm{N} 4$ are the neighbor nodes of the mobile node $\mathrm{N} 1$.

\section{PERFORMANCE METRICS}

Various metrics are available to analyze the performances of the MANET routing protocols. Following metrics are taken into account for our simulation based analysis [15].

\section{(1) Throughput}

Throughput is the total data transmitted from the source node to the destination node in a time unit which is expressed in Kilobits per second (Kbps).

$$
\text { Throughput }=\frac{(\text { Total Received Bytes xפ) }}{(\text { Simulation Time } \times 1024)}
$$

Unit of throughput is Kbps. Higher values of the throughput provide better performance.

\section{(2) Packet Delivery Ratio (PDR)}

Packet Delivery Ratio is the fraction of amount of received packets to the amount of sent packets.

$$
\mathrm{PDR}=\frac{\text { Amount of Received Packets }}{\text { Amount of Packets Sent }} \times 100 \%
$$

PDR is derived in \% (percentage). Higher values of PDR provide better performance.

\section{(3) End to End Delay (EED)}

EED is the average time interval between packets generated at the source and effective delivery of these packets at the destination. EED is the fraction of delay sum to the packets received.

$$
\mathrm{EED}=\frac{\text { Delay Sum }}{\text { Packets Received }}
$$

EED is derived in mille seconds (ms). Lower values of EED provide better performance.

\section{(4) Packet Loss (PL)}

Packet loss is the difference of total packets sent and the total packets received.

PL = (Total Packets Sent $)-($ Total Packets Received $)$

Packet loss is derived in number of packets.

\section{(5) Normalized Routing Load (NRL)}

NRL is the ratio of the numbers of transmitted routing packets to the number of packets received [23].

$$
\mathrm{NRL}=\frac{\text { Number of Routing Packets Sent }}{\text { Number of Packets Received }}
$$

Larger values of NRL provide better and enhanced 
performance however, higher values of NRL leads to reduced efficiency in terms of ingestion of bandwidth.

\section{NETWORK SIMULATOR -3 (NS -3)}

We have used NS-3(Network Simulator-3) version 3.13 for our simulation based experiments. NS-3 is an open source discrete-event based network simulating software developed specially for research and educational purposes. NS-3 is licensed under GNU GPLv2 license and it is publicly available for research and development. The NS-3 project builds a solid simulation core, easy to use and debug. "NS-3 core caters the needs of the simulation workflow, from the simulation configuration to trace collection and analysis. The NS-3 simulation core supports research on both IP and non-IP based networks" [24]. Majority of NS-3 users emphases on wireless/IP simulations. NS-3 is developed using $\mathrm{C}++$ high level programming language with the optional python bindings. NS-3 has enhanced simulation reliability. It is not backward adjusted with NS-2 (Network Simulator-2). NS-3 is built from the scratch to replace application program interfaces (APIs) of NS-2. Some modules of NS2 have been ported in it. NS-3 does not support APIs of
NS-2 [15]. NS-3 supports real-time schedulers which simplifies number of "simulations-in-the-loop". Packets generated by the NS-3 can be emitted and receive on real network devices. NS-3 is aligned with the simulation needs of modern networking research.

\section{RESULTS AND DISCUSSIONS}

Simulation based experiments and performance comparison of mobile ad-hoc network routing protocols (AODV, DSDV and OLSR) have been carried out in two different scenarios, in first scenario (SS-I), we varied node density and in another (SS-II), varied pause time have been taken into account. The simulation scenarios and obtained results are illustrated in the following tables and graphs.

\section{A. Simulation Scenario - I (SS-I)}

General Network parameters that have been taken into account for simulation scenario-I are mentioned in the Table 1. In SS-I, number of nodes have been varied keeping 10 number of source/sink connection fixed.

Table 1. Network Parameters for SS-I

\begin{tabular}{|c|c|c|}
\hline 1 & Number of Nodes & $30,40,50,60,70,80,90,100$ \\
\hline 2 & Simulation Time & 150 seconds \\
\hline 3 & Pause Time & No pause time \\
\hline 4 & Wi-Fi mode & Ad-hoc \\
\hline 5 & Wi-Fi Rate & $7.5 \mathrm{dBm}$, \\
\hline 6 & Transmit Power & Random Waypoint mobility model \\
\hline 7 & Mobility model & 10 \\
\hline 8 & No.of Source/Sink & 2048 bits per second $(2.048$ Kbps $)$ \\
\hline 9 & Sent Data Rate & 64 Bytes \\
\hline 10 & Packet Size & AODV,DSDV and OLSR \\
\hline 11 & Node Speed & $300 x 1500 \mathrm{~m}$ \\
\hline 12 & Protocols used & Friis loss model \\
\hline 13 & Region & \\
\hline 14 & Loss Model & \\
\hline
\end{tabular}

\section{(1) Throughput}

calculate the throughput as per throughput metrics, results

Captured experimental packet data have been used to

Table 2. Throughput in Kbps

\begin{tabular}{|c|c|c|c|}
\hline No. of Nodes & AODV & DSDV & OLSR \\
\hline 30 & 16.04 & 14.95 & 18.27 \\
\hline 40 & 17.93 & 14.3 & 16.93 \\
\hline 50 & 14.47 & 12.64 & 17.99 \\
\hline 60 & 1.87 & 14.87 & 18.91 \\
\hline 70 & 9.73 & 14.58 & 18.99 \\
\hline 80 & 11.62 & 15.6 & 18.60 \\
\hline 90 & 0.68 & 13.47 & 17.47 \\
\hline 100 & 1.42 & 13.58 & 18.45 \\
\hline
\end{tabular}

Fig. 4 explores performance of AODV, DSDV and OLSR in terms of average throughput with the increasing node density. OLSR has shown better performance as compared to AODV and DSDV. AODV has performed 
better than DSDV for smaller number of nodes however, DSDV has shown better performance for large number of nodes.

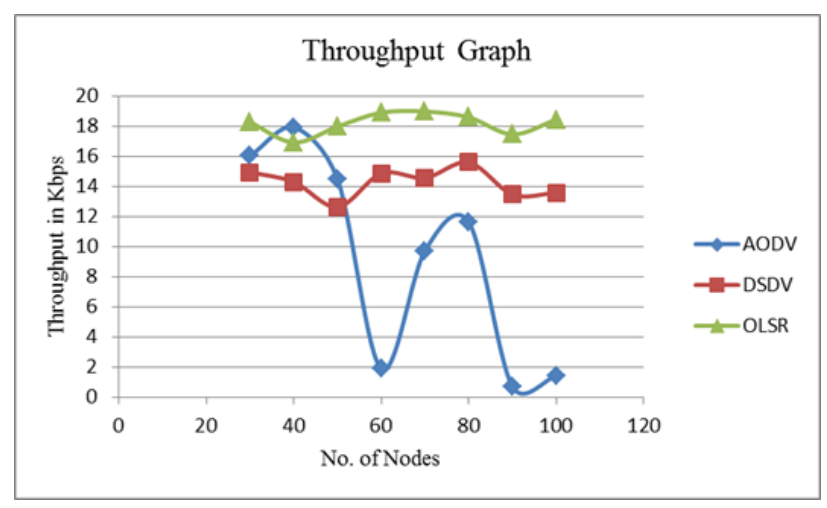

Fig.4. Throughput Over No. of Nodes

\section{(2) Packet Delivery Ratio (PDR)}

Data of Table 3 have been extracted from the packet data obtained from the experiments and the metrics of the packet delivery ratio.

Table 3. Packet Delivery Ratio in \%

\begin{tabular}{|c|c|c|c|}
\hline No. of Nodes & AODV & DSDV & OLSR \\
\hline 30 & 80.22 & 74.73 & 91.33 \\
\hline 40 & 89.63 & 71.52 & 84.67 \\
\hline 50 & 72.33 & 63.22 & 89.93 \\
\hline 60 & 9.35 & 74.35 & 94.55 \\
\hline 70 & 48.63 & 72.88 & 94.97 \\
\hline 80 & 58.08 & 77.98 & 93.00 \\
\hline 90 & 3.42 & 67.33 & 87.37 \\
\hline 100 & 7.08 & 67.88 & 92.25 \\
\hline
\end{tabular}

From the results, packet delivery ratio of the OLSR routing protocol is found better than that of AODV and DSDV. Here, AODV has performed well for smaller number of nodes but, DSDV has shown better results for higher number of nodes.

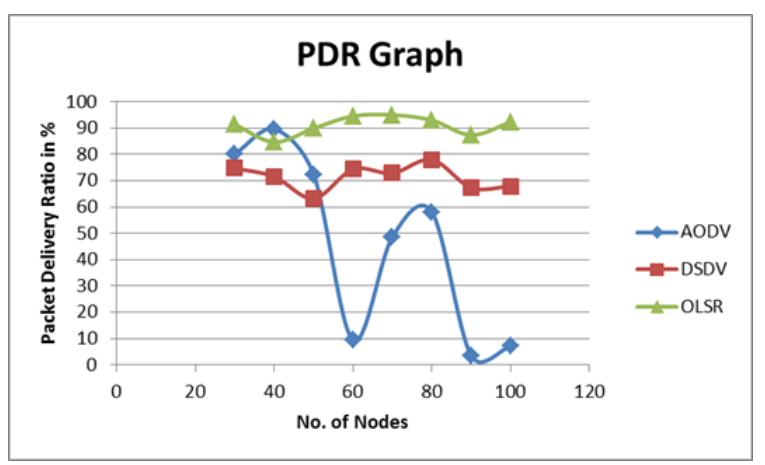

Fig.5. PDR Over No. of Nodes

\section{(3) End to End Delay (EED)}

Table 4 shows the data sheet of end to end delay calculated from the experimental data and the metrics.
Table 4. End to End Delay in Mille Seconds

\begin{tabular}{|c|c|c|c|}
\hline $\begin{array}{c}\text { No. of } \\
\text { Nodes }\end{array}$ & AODV & DSDV & OLSR \\
\hline 30 & 6.17 & 8.45 & 2.37 \\
\hline 40 & 2.89 & 9.96 & 4.53 \\
\hline 50 & 9.56 & 14.55 & 2.8 \\
\hline 60 & 242.38 & 8.62 & 1.44 \\
\hline 70 & 26.41 & 9.30 & 1.33 \\
\hline 80 & 18.04 & 7.06 & 1.88 \\
\hline 90 & 706.71 & 12.13 & 3.62 \\
\hline 100 & 327.94 & 11.83 & 2.10 \\
\hline
\end{tabular}

OLSR has shown better results as compare to the rest two routing protocols however, when comparing AODV and DSDV, the AODV has performed fine for smaller number of nodes and the DSDV has shown better performance for higher number of nodes.

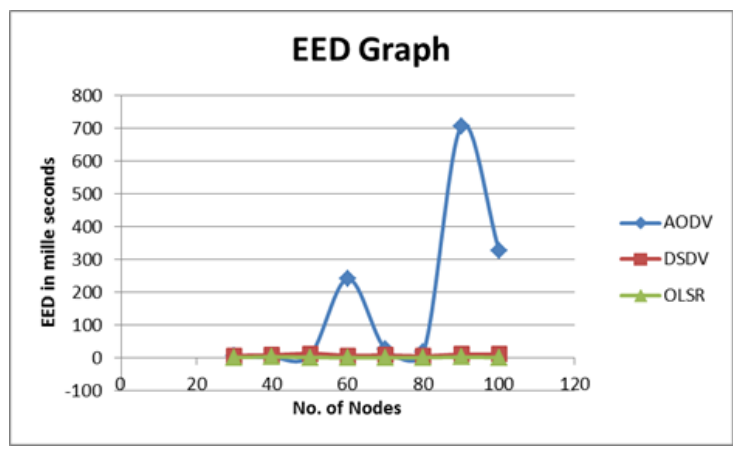

Fig.6. EED Over No. of Nodes

(4) Packet Loss (PL)

Here, OLSR has least number of packet losses as compare to AODV and DSDV. Table 5 explores the PL of all the three routing protocols.

Table 5. Packet Loss in No. of Packets

\begin{tabular}{|c|c|c|c|}
\hline No. of Nodes & AODV & DSDV & OLSR \\
\hline 30 & 1187 & 1516 & 520 \\
\hline 40 & 622 & 1709 & 920 \\
\hline 50 & 1660 & 2207 & 604 \\
\hline 60 & 5439 & 1539 & 327 \\
\hline 70 & 3082 & 1627 & 302 \\
\hline 80 & 2515 & 1321 & 420 \\
\hline 90 & 5795 & 1960 & 758 \\
\hline 100 & 5575 & 1927 & 465 \\
\hline
\end{tabular}

When comparing AODV and DSDV, AODV has lesser packet losses for smaller number of nodes and the DSDV has less number of these losses for higher number of nodes. 


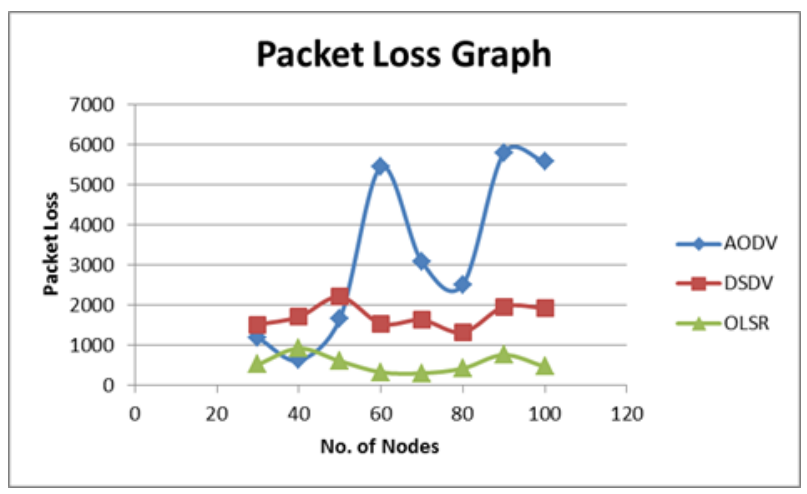

Fig.7. Packet loss Over No. of Nodes

\section{(5) Normalized Routing Load (NRL)}

NRL data sheet shows better performance of the OLSR as compare to AODV and DSDV.

Table 6. NRL

\begin{tabular}{|c|c|c|c|}
\hline No. of Nodes & AODV & DSDV & OLSR \\
\hline 30 & 0.802 & 0.747 & 0.913 \\
\hline 40 & 0.896 & 0.715 & 0.847 \\
\hline 50 & 0.723 & 0.632 & 0.899 \\
\hline 60 & 0.094 & 0.744 & 0.946 \\
\hline 70 & 0.486 & 0.729 & 0.95 \\
\hline 80 & 0.581 & 0.78 & 0.93 \\
\hline 90 & 0.034 & 0.673 & 0.874 \\
\hline 100 & 0.071 & 0.679 & 0.923 \\
\hline
\end{tabular}

Like in other metrics discussed above, AODV has better values for smaller number of nodes and the DSDV has performed well for higher number of nodes.

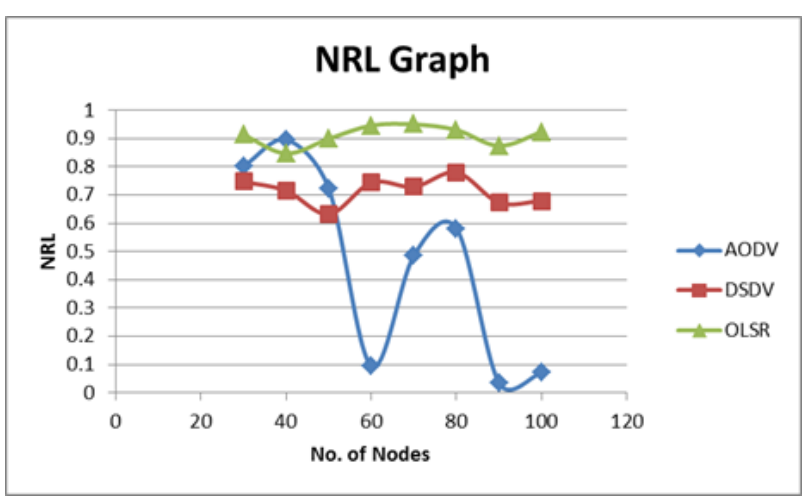

Fig.8. NRL Over No. of Nodes

\section{B. Simulation Scenario - II (SS-II)}

General Network parameters for SS-II have been chosen as per Table - 3.7. In SS-II, pause times of nodes have been varied while keeping 10 numbers of fixed source/sink connections. Random waypoint mobility model has been considered for this experiment.
Table 7. Network Parameters for SS-II

\begin{tabular}{|c|c|c|}
\hline 1 & Number of Nodes & 50 \\
\hline 2 & Simulation Time & 150 seconds \\
\hline 3 & Pause Time (Seconds) & $5,10,15,20,25,30$ \\
\hline 4 & Wi-Fi mode & Ad-hoc \\
\hline 5 & Wi-Fi Rate & 2Mbps (802.11b) \\
\hline 6 & Transmit Power & $7.5 \mathrm{dBm}$, \\
\hline 7 & Mobility model & $\begin{array}{c}\text { Random Waypoint mobility } \\
\text { model }\end{array}$ \\
\hline 8 & No. of Source/Sink & 10 \\
\hline 9 & Sent Data Rate & $\begin{array}{l}2048 \text { bits per second } \\
(2.048 \mathrm{Kbps})\end{array}$ \\
\hline 10 & Packet Size & 64 Bytes \\
\hline 11 & Node Speed & $20 \mathrm{~m} / \mathrm{s}$ \\
\hline 12 & Protocols used & AODV,DSDV and OLSR \\
\hline 13 & Region & $300 \times 1500 \mathrm{~m}$ \\
\hline 14 & Loss Model & Friis loss model \\
\hline
\end{tabular}

\section{(1) Throughput}

Here, average throughput of the OLSR is better found as compare to AODV and DSDV routing protocols.

Table 8. Throughput in Kbps

\begin{tabular}{|c|c|c|c|}
\hline $\begin{array}{c}\text { Pause Time } \\
\text { in Seconds }\end{array}$ & AODV & DSDV & OLSR \\
\hline 5 & 2.88 & 12.96 & 17.91 \\
\hline 10 & 5.20 & 13.25 & 17.80 \\
\hline 15 & 13.55 & 14.31 & 17.48 \\
\hline 20 & 16.27 & 12.75 & 18.74 \\
\hline 25 & 16.42 & 12.21 & 18.69 \\
\hline 30 & 14.21 & 12.76 & 18.27 \\
\hline
\end{tabular}

When comparing AODV and DSDV, AODV is found better performing for higher node pause times, whereas DSDV has shown better results for smaller values of the node pause time.



Fig.9. Throughput Over Pause Time 


\section{(2) Packet Delivery Ratio (PDR)}

As per data sheet shown in Table 9, OLSR protocol has shown better results as compare to AODV and DSDV.

Table 9. Packet Delivery Ratio in \%

\begin{tabular}{|c|c|c|c|}
\hline $\begin{array}{c}\text { Pause Time } \\
\text { in Seconds }\end{array}$ & AODV & DSDV & OLSR \\
\hline 5 & 14.42 & 64.82 & 89.55 \\
\hline 10 & 25.98 & 66.23 & 89.02 \\
\hline 15 & 67.77 & 71.53 & 87.40 \\
\hline 20 & 81.37 & 63.73 & 93.72 \\
\hline 25 & 82.10 & 61.03 & 93.45 \\
\hline 30 & 71.07 & 63.78 & 91.35 \\
\hline
\end{tabular}

When comparing AODV and DSDV, AODV has shown better performance for higher node pause times, whereas DSDV has shown better results for the lower pause times.

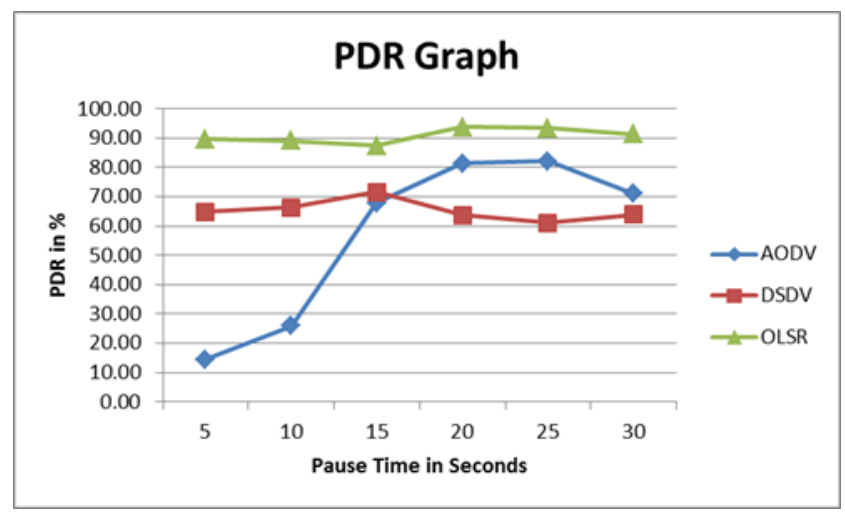

Fig.10. PDR Over Pause Time

\section{(3) End to End Delay (EED)}

Here, among all the three routing protocols, OLSR has shown better performance in terms of delay.

Table 10. EED in Mille Seconds

\begin{tabular}{|c|c|c|c|}
\hline $\begin{array}{c}\text { Pause Time } \\
\text { in Seconds }\end{array}$ & AODV & DSDV & OLSR \\
\hline 5 & 148.410 & 13.570 & 2.920 \\
\hline 10 & 71.220 & 12.750 & 3.080 \\
\hline 15 & 11.890 & 9.950 & 3.600 \\
\hline 20 & 5.730 & 14.230 & 1.680 \\
\hline 25 & 5.450 & 15.960 & 1.750 \\
\hline 30 & 10.180 & 14.200 & 2.370 \\
\hline
\end{tabular}

AODV has larger delays for lesser pause times but it has lesser delay values for higher node pause times. DSDV has lesser delay values for lesser node pause times as compare to AODV.

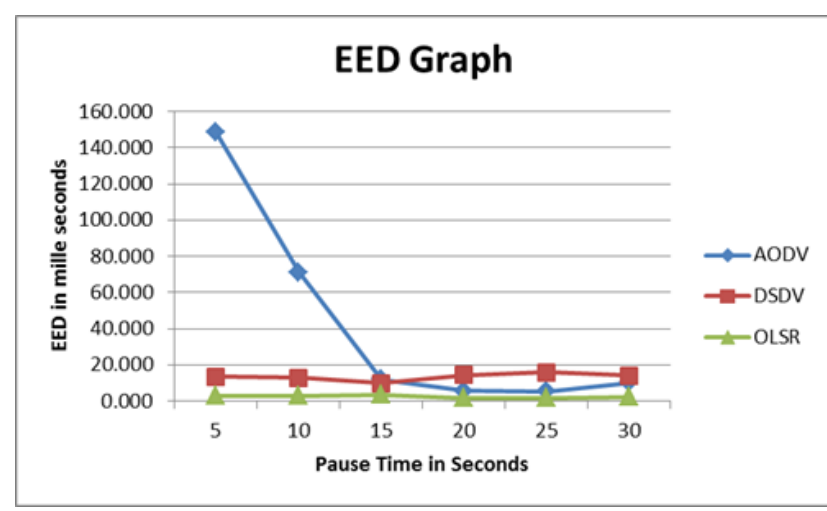

Fig.11. EED Over Pause Time

\section{(4) Packet Loss (PL)}

As compare to AODV and DSDV, OLSR has lesser packet losses for the node pause time variation.

Table 11. Packet loss in No. of packets

\begin{tabular}{|c|c|c|c|}
\hline $\begin{array}{c}\text { Pause Time } \\
\text { in Seconds }\end{array}$ & AODV & DSDV & OLSR \\
\hline 5 & 5135 & 2111 & 627 \\
\hline 10 & 4441 & 2026 & 659 \\
\hline 15 & 1934 & 1708 & 756 \\
\hline 20 & 1118 & 2176 & 377 \\
\hline 25 & 1074 & 2338 & 393 \\
\hline 30 & 1736 & 2173 & 519 \\
\hline
\end{tabular}

When Comparing AODV and DSDV, DSDV has lesser packet losses for lesser pause time values and AODV has lesser packet losses for higher node pause times.

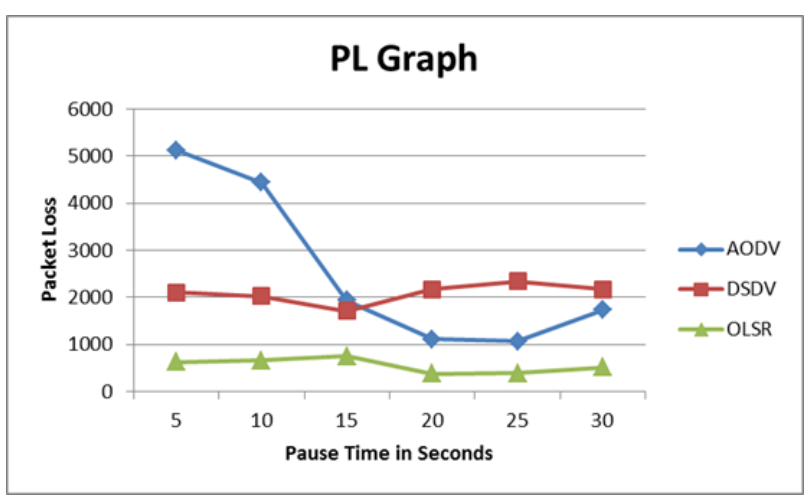

Fig.12. PL Over Pause Time

(5) Normalized Routing Load (NRL)

NRL values of OLSR protocol have shown better results as compare to AODV and DSDV routing protocols. 
Table 12. Normalized Routing Load

\begin{tabular}{|c|c|c|c|}
\hline $\begin{array}{c}\text { Pause Time } \\
\text { in Seconds }\end{array}$ & AODV & DSDV & OLSR \\
\hline 5 & 0.144 & 0.648 & 0.896 \\
\hline 10 & 0.260 & 0.662 & 0.890 \\
\hline 15 & 0.678 & 0.715 & 0.874 \\
\hline 20 & 0.814 & 0.637 & 0.937 \\
\hline 25 & 0.821 & 0.610 & 0.935 \\
\hline 30 & 0.711 & 0.638 & 0.914 \\
\hline
\end{tabular}

When comparing AODV and DSDV, AODV has performed better for higher pause times and the DSDV has better results for lesser node pause times. Fig. 13 illustrates the better performance of the OLSR routing protocol as compare to AODV and DSDV. The green line in the graph shows the performance of the OLSR routing protocol, likewise; blue line represents the performance of the AODV protocol and the brown line represents the performance of the DSDV routing protocol. These lines represent performance of all the three routing protocols with respect to increasing node density and the node pause times.

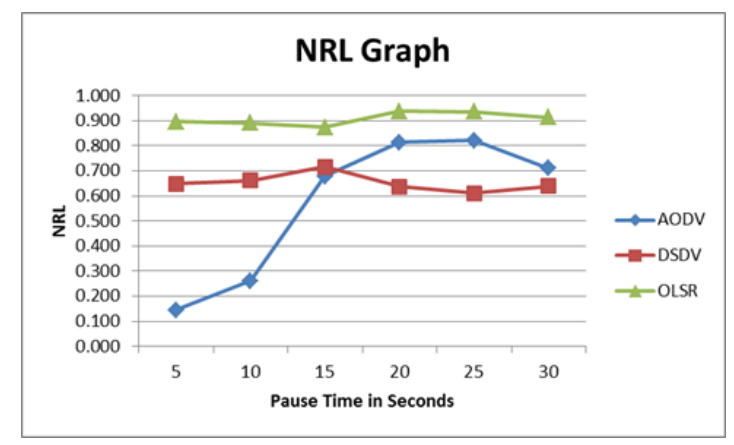

Fig.13. NRL Over Pause Time

\section{CONCLUSIONS}

As per the simulation based experiments in both the scenarios (Scenario-I \& Scenario-II), it is noticed that the performance of the OLSR routing protocol is better in all the metric calculations as compare to the DSDV and AODV routing protocols. In scenario-I, throughput of the OLSR is better, whereas AODV and DSDV are concerned, initially throughput of the AODV is better, but after certain point of time, it decreases. DSDV is performing well as compare to AODV, in terms of throughput. In rest metrics too, OLSR has good results as compare to AODV and DSDV. In scenario-II, OLSR is performing well as compared to rest two routing protocols. As far as AODV and DSDV are concerned, DSDV performed well as compare to AODV in all the metrics we used here. However, in some cases, performance of the DSDV routing protocol is found improved. In some other cases, performance of AODV is found well. These conclusions are totally based on the NS-3, version 3.13, and the network parameters that we set for our analysis. However, performance of the MANET routing protocols depends on various factors like, transmit power, no. of source/sink connections, node density, node velocity, transmission region, transmission range, type of load traffic, Wi-Fi rate and packet size etc. Future research can be carried out by varying the network parameters as well as protocol parameters for further improvement in the MANET routing protocols.

\section{ACKNOWLEDGMENT}

We thank Dr.R.S.Yadava and Dr.Chandan Kumar Rai, Programmers of Computer Centre, Banaras Hindu University, Varanasi, India, for their kind support and encouragement.

\section{REFERENCES}

[1] Mobile ad hoc networks (MANET). http: //www.ietf.org/html.charters/manet-charter.html, IETF Working Group Charter 1997.

[2] Anuj K. Gupta, Harsh Sadawarti, Anil K. Verma, "Review of various Routing Protocols for MANETs", International Journal of Information \& Electrical Engineering, Article No. 40, 1(3): 251-259, November 2011.

[3] E.M. Royer, C-K. Toh, "A Review of Current Routing Protocols for Ad Hoc Mobile Wireless Networks", IEEE Personal Communications Magazine, April 1999, pp. 4655.Kredo, K. and P. Mohapatra, Medium access control in wireless sensor networks. Computer Networks, 2007. 51(4): p. 961-994.

[4] H. Tafazolli, "A Survey of QoS Routing Solutions for Mobile Ad Hoc Networks", IEEE Communications Surveys \& Tutorials, Vol. 9, No. 2, pp. 50-70, 2007.

[5] Arunima Patel, Sharda Patel, Ashok Verma "A Review of performance Evaluation of AODV Protocol in Manet With and Without Black HoleAttack" International Journal of Emerging Technology and Advanced Engineering ISSN 22502459,Volume 2, Issue 11, November 2012.

[6] H. Pucha, S. M. Das, and Y. C. Hu, "The performance impact of traffic patterns on routing protocols in mobile ad hoc networks," Computer Networks, vol. 51, no. 12, pp. 359 5-3616, 2007.

[7] Huhtonen, "Comparing AODV and OLSR routing protocols," presented at Telecommunications Software and Multimedia, pp. 1- 9, 2004.

[8] M. Benzaid, P. Minet, and K. AI Agha, "Integrating fast mobility in the OLSR routing protocol," presented at the fourth IEEE Conference in Mobile and Wireless Communications, pp. 1- 5, 2002.

[9] G. Jayakumar and G. Gopinath, "Performance comparison of two ondemand routing protocols for ad-hoc networks based on random way point mobility model," American Journal of Applied SCiences, vol. 5, no. 6,pp. 659664,2008 .

[10] N. Taing, S. Thipchaksurat, R. Varakulsiripunth, and H. Ishii, "Performance improvement of dynamic source routing protocol for multimedia services in mobile ad hoc network," presented at the 1st International Symposium on Wireless Pervasive Computing, pp. 1- 5, 2006.

[11] F. D. Rango, J.-c. Cano, M. Fotino, C. Calafate, P. Manzoni, and S. Marano, "OLSR vs DSR: A comparative analysis of proactive and reactive mechanisms from an energetic point of view in wireless ad hoc networks," Computer Communications, vol. 31, no. 16, pp. 38433854, 2008. 
[12] S. Giannoulis, C. Antonopoulos, E. Topalis, and S. Koubias, "ZRP versus DSR and TORA: A comprehensive survey on ZRP performance," presented at the 10th IEEE Conference on Emerging Technologies and Factory Automation (ETFA ' 05), pp. 1-8, 2005.

[13] F. Yu, Y. Li, F. Fang, and Q. Chen, "A new TORA-based energy aware routing protocol in mobile ad hoc networks," presented at the 3rd IEEE/IFIP International Conference in Central Asia on Internet, ICI ' 07, pp. 1-4, 2007.

[14] Teressa Longjam and Neha Bagoria. "Comparative Study of Destination Sequenced Distance Vector and Ad-hoc on-demand Distance Vector Routing Protocol of Mobile Ad-hoc Network". IJSRP, vol. 3, Issue 2, February 2013.

[15] Rakesh Kumar Jha, Pooja Kharga. "A Comparative Performance Analysis of Routing Protocols in MANET using NS3 Simulator", in IJCNIS - MEC Publications, vol. 4 pp.62-68. March, 2015.

[16] D.Kumar \& S.C.Gupta. "Transmission Range, Density \& Speed based Performance Analysis of Ad Hoc Networks". African Journal of Computing \& ICT. Vol. 8.No. 1-March, 2015.

[17] Rajneesh Kumar Gujral, Jitender Grover, Anjali. “An Analysis of Network Survivability with Variable Transmission Range and Mobility on AODV over MANET". TECHNICA, vol. 5, No.2, Jan, 2013.

[18] [Online].Available:https://en.wikipedia.org/wiki/Ad_hoc_ On Demand_Distance_Vector_Routing.

[19] Vinay P.Virada "Securing And Preventing Aodv Routing Protocol From Black Hole Attack Using Counter Algorithm" International Journal ofEngineering Research \& Technology (IJERT) Vol. 1 Issue 8, October 2012 ISSN: 22780181

[20] AshishBagwari, Raman Jee,Pankaj Joshi and Sourabh Bisht " Performance of AODV Routing Protocol with increasing the MANET Nodes and its effects on QoS of Mobile Ad hoc Networks " 2012 International Conference on Communication Systems and Network Technologies 9780769546926/12 @ 2012 IEEE.

[21] Sreekanth Vakati, Dr.Ch.Balaswamy, "Performance Analysis of Routing Protocols in Mobile Ad Hoc Networks", July 2013.

[22] Dilpreet Kaur, Naresh Kumar, "Comparative Analysis of AODV, OLSR, TORA, DSR and DSDV Routing protocols in Mobile Ad-Hoc Networks," in IJCNIS journal, vol.5, no.3, pp.39, 2013.

[23] Qutaiba Razouqi, Ahmed Boushehri, Mohamed Gaballah, Lina Alsaleh, "Extensive Simulation Performance Analysis for DSDV, DSR, and AODV MANET Routing Protocols. IEEE 2013.

[24] [Online].Available: https://www.nsnam.org/overview/what-is-ns-3/

[25] Ali Khosrozadeh, Abolfazle Akbari, Maryam Bagheri and Neda Beikmahdavi, "A New Algorithm AODV Routing Protocol in Mobile ADHOC Networks", published in International Journal of Latest Trends in computing, vol.2, No.3, September 2011.

[26] D.Loganathan, P.Ramamoorthy, "Performance Analysis of Enhanced DSDV Protocol for Efficient Routing In Wireless Ad Hoc Networks", published in International
Journal Of Engineering And Science Vol.2, Issue $10 \mathrm{pp}$. 01-08, April 2013.

[27] Charles E.Perkins, T.J. Watson, Pravin Bhagwat. Proceeding SIGCOMM '94 Proceedings of the conference on Communications architectures, protocols and applications Pages 234-244, ACM New York, NY, USA (c)1994.

\section{Authors' Profiles}

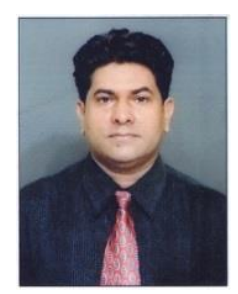

Lakshman Naik.L received Bachelor of Engineering degree in Electronics and Communication Engineering from Gulbarga University, Gulbarga, India. Currently, he has been pursuing Ph.D., in Indian Institute of Technology (Banaras Hindu University), Varanasi, India. Now, he is working as a Maintenance Engineer at Computer Centre of the Banaras Hindu University, in Varanasi, India. He has more than 10 years of experience in maintaining computer Networks, having 5 years of research experience in Engineering and Educational fields. His research interest includes Computer Networks, Wired and Wireless Communication, Mobile Ad hoc Networks, and Network Routing Protocols. He has published several research papers in various international journals.



Dr. R.U.Khan is an Associate Professor in Department of Electronics Engineering, Indian Institute of Technology (Banaras Hindu University), Varanasi, India. $\mathrm{He}$ received B.Tech, M.Tech and Ph.D. degree from Banaras Hindu University, Varanasi, India. $\mathrm{He}$ has more than 36 years of experience in teaching. His research interests focus on Microwave solid State Devices, Microelectronics, Opto-electronics devices and Computer Networks. He is guiding for several research scholars under Indian Institute of Technology (Banaras Hindu University), Varanasi, India. He has been published many research articles in National, International Journals and conferences.

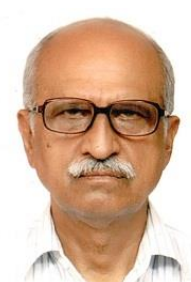

Prof. R.B. Mishra is a Professor in Department of Computer Science and Engineering, Indian Institute of Technology (Banaras Hindu University), Varanasi, India. He received B.Sc.( Engg.), M.Tech (Control) and Ph.D., degree from Banaras Hindu University, Varanasi, India. He has more than 35 years of experience in teaching. His research interests focus on Artificial Intelligence, Multi-agent Systems, Semantic Web and Computer Networks. He has guided $16 \mathrm{Ph} . \mathrm{D}$ scholars under Indian Institute of Technology (Banaras Hindu University), Varanasi, India. He has been published more than 230 research articles in Journals and conferences.

How to cite this paper: Lakshman Naik.L, R.U.Khan, R.B.Mishra,"Analysis of Node Density and Pause Time Effects in MANET Routing Protocols using NS-3", International Journal of Computer Network and Information Security(IJCNIS), Vol.8, No.12, pp.9-17, 2016.DOI: 10.5815/ijcnis.2016.12.02 